\title{
Seasonal variability in aerosol optical and physical characteristics estimated using the application of the Ångström formula over Mohal in the northwestern Himalaya, India
}

\author{
Raj Paul Guleria ${ }^{1}$, Jagdish Chandra Kuniyal ${ }^{1, *}$, \\ NAnd Lal Sharma ${ }^{1}$ and Pitamber Prasad Dhyani ${ }^{2}$ \\ ${ }^{1}$ G.B. Pant Institute of Himalayan Environment and Development, Himachal Unit, Mohal-Kullu 175 126, India. \\ ${ }^{2}$ G.B. Pant Institute of Himalayan Environment and Development, Kosi-Katarmal, Almora 263 643, India. \\ ${ }^{*}$ Corresponding author.e-mail: jckuniyal@gmail.com jckuniyal@rediffmail.com
}

Investigations of aerosol optical and physical characteristics using the application of Ångström formula and second order polynomial fit were carried out from April 2006 to March 2009 at Mohal in the Kullu valley. The measurements of spectral aerosol optical depths (AODs) were conducted using multiwavelength radiometer (MWR). The AOD at $0.5 \mu \mathrm{m}$ wavelength on daily basis (mean \pm standard deviation) for the entire three-year study period is obtained as $0.24 \pm 0.08$. Seasonal variations show the highest AOD at $0.5 \mu \mathrm{m}$ wavelength with $\sim 0.34 \pm 0.08$ during pre-monsoon (April-July), followed by $\sim 0.26 \pm 0.08$ during monsoon (August-September), $\sim 0.21 \pm 0.05$ during post-monsoon (OctoberNovember) and $\sim 0.20 \pm 0.07$ during winter (December-March). The seasonal values indicate that the $\mathrm{AOD}$ at $0.5 \mu \mathrm{m}$ wavelength is decreasing from pre-monsoon to winter with a notable reduction around 41\%. The Angström parameters using least square method is not found appropriate for size distribution particularly when coarse mode aerosols dominate. The coefficients of second order polynomial fit are more appropriate for the discrimination of aerosol size or irrespective to the dominance of either of the aerosols size. The difference in coefficient of polynomial fit is used to get confirmation on the dominant mode during different seasons. Study reveals that about $93 \%, 72 \%$ and $59 \%$ of AOD spectra are dominated by a wide range of fine mode fractions or mixture of modes during post-monsoon, winter and monsoon, respectively. On the other hand, during pre-monsoon, $72 \%$ of AOD spectra are found to be dominated by coarse mode aerosols.

\section{Introduction}

Aerosols are produced by a variety of natural as well as anthropogenic activities, and get distributed in the atmosphere through turbulent mixing and transport which result in a large variability in their size distribution (Meszaros 1981; Reist 1984; Eck et al 1999; Kedia and Ramachandran
2009). At global level, the natural sources (e.g., volcanic eruption, transport of desert dust, etc.) of aerosols are dominant over the anthropogenic sources (e.g., biomass burning, vehicular emission, etc.), but at regional level the contribution of anthropogenic sources of aerosol is significant (Ramanathan et al 2001). The long-range transport of desert dust also contributes to the aerosol

Keywords. Aerosol optical depth; Ångström exponent; second order polynomial fit; multi-wavelength radiometer. 
size distribution (ASD) (Moorthy and Satheesh 2000; Gogoi et al 2008; Kedia and Ramachandran $2009,2010)$. The investigation on aerosol transport is carried out by Kuniyal et al (2009) and Guleria et al (2011a, 2011b, 2012) at Mohal in the northwestern part of the Indian Himalaya. Their investigations suggest that Mohal gets affected by dust aerosol due to its transport from the western deserts. The understanding of the variability in the ASD is the prime concern to quantify the radiative effect of aerosol, but it is a challenging task due to inadequate information (IPCC 2007).

Spectral aerosol optical depth (AOD, $\left.\tau_{p \lambda}\right)$ contains information pertaining to ASD and is used to compute Ångström exponent $(\alpha)$ and turbidity coefficient ( $\beta$ ) using Ångström Power Law (Schuster et al 2006; Kaskaoutis et al 2007, 2010; Gogoi et al 2008; Kedia and Ramachandran 2009; Sharma et al 2010, 2011). Angström exponent is a quantitative indicator of the ASD and the turbidity coefficient is a measure of total aerosol loading in a vertical column (Schuster et al 2006; Gogoi et al 2008; Kedia and Ramachandran 2009; Kaskaoutis et al 2010; Sharma et al 2011). In general, Angström Power Law is applicable to the entire wavelength spectrum, only if the ASD fits to the Junge Power Law (Kedia and Ramachandran 2009). But, when the spectral range is extended and the ASD is generally multi-modal, it can introduce significant errors (Kaskaoutis et al 2010). Therefore, the use of Angström Power Law is not applicable to all the environments and regions (Eck et al 1999, 2001; Reid et al 1999; Kaskaoutis and Kambezidis 2006; Kaskaoutis et al 2007; Kedia and Ramachandran 2009; Kalapureddy and Devara 2010). When the spectral range is extended, Ångström Power Law departs from its linear behaviour of $\ln \tau_{p \lambda}$ versus $\ln \lambda$ and this results in different values of $\alpha$ for different wavelength ranges (Kedia and Ramachandran 2009). This leads to a curvature in $\tau_{p \lambda}$ which contains useful information about the ASD (Eck et al 1999). The value of $\alpha \leq 1$ indicates that the size distributions are dominated by coarse mode aerosols such as dust or sea salt. The value of $\alpha \geq 2$ indicates that the size distributions are dominated by fine mode aerosols that are usually attributed to anthropogenic activities (Eck et al 1999; Schuster et al 2006).

Numerous measurements to investigate the curvature in AOD spectra and impact assessments are reported from the Indian region in recent years (Kedia and Ramachandran 2009; Kalapureddy and Devara 2010; Kaskaoutis et al 2010, 2011; Kedia et al 2010; Sharma et al 2010; Kumar et al 2011). However, these measurements are focused either on urban landmass or oceans adjacent to densely populated coastal regions. Investigations from remote and sparsely inhabited regions of the mountain ecosystems are very rare. This paper deals with the study of characterization of atmospheric aerosols, investigation of the errors and uncertainties computed from the application of the Angström Power Law (linear fit) as well as from the second order polynomial fit in the $\ln \tau_{p \lambda}$ versus $\ln \lambda$ relationship. This study also highlights the seasonal variability in contribution of fine mode as well as coarse mode aerosols from different source origins. Thus, the reported results on seasonal variations in aerosol characteristics from the Kullu valley located in the northwestern Indian Himalaya will be useful in modelling the radiative effect of aerosols at a regional level.

\section{Experimental site description and surface meteorology}

The present experimental site - Mohal $\left(31.9^{\circ} \mathrm{N}\right.$, $77.12^{\circ} \mathrm{E}, 1154 \mathrm{~m}$ amsl) is located in the Kullu valley of the northwestern part of Indian Himalaya (figure 1). This part of the Indian Himalaya is mostly affected due to dust aerosol transport from

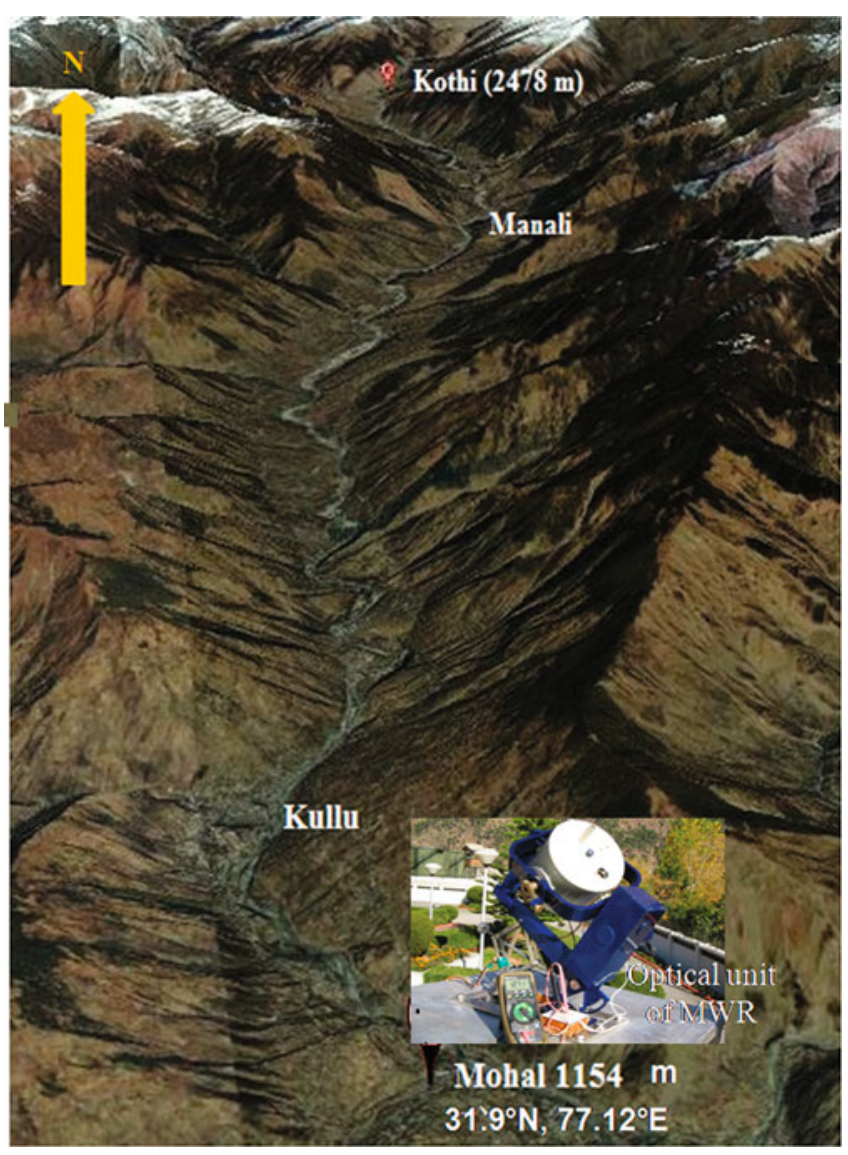

Figure 1. View of the Kullu valley (source: Google Earth), showing installation location of MWR. 
the desert prone regions such as the Sahara Desert (Kuniyal et al 2009; Guleria et al 2011a, 2011b, 2012), the Taklimakan Desert (Guleria et al 2011b, 2012), and the Thar Desert (Kuniyal et al 2009; Guleria et al 2011a, 2012) during pre-monsoon and the smoke aerosol transport from the plains of India such as Punjab (Guleria et al 2011b, 2012) during post-monsoon. The Kullu valley is surrounded by mountains ranging from $3000-5000 \mathrm{~m}$. The River Beas flows in the middle part of this valley. The Kullu valley is about $80-\mathrm{km}$ long and $2-\mathrm{km}$ wide. It begins from Larji (957 $\mathrm{m}$ amsl) in the lower Beas basin in the south and extends up to the Rohtang crest (4038 $\mathrm{m}$ amsl) in the upper Beas basin in the north (Kuniyal et al 2009). Mohal is a semi-urban experimental site under the programme of Aerosols Radiative Forcing over India (ARFI), a national project under the Indian Space Research Organization Geosphere Biosphere Programme (ISRO-GBP) (Kuniyal et al 2009; Guleria et al 2011b).

\subsection{Surface meteorology}

It is a well-known fact that meteorology and atmospheric dynamics play an important role in affecting and modulating the spatio-temporal variabilities in aerosol characteristics over any region (Singh et al 2004; Ganguly et al 2006; Kaskaoutis et al 2009). Therefore, following Kuniyal et al (2009) and Guleria et al (2011a), the entire observation period is classified into four local seasons: pre-monsoon (April-July), monsoon (AugustSeptember), post-monsoon (October-November) and winter (December-March) depending on the prevailing local meteorological parameters and climatic characteristics. The monthly variations of meteorological parameters are shown in figure 2 . The surface wind is noticed as high as $1.4 \mathrm{~ms}^{-1}$ during August 2006. In general, the surface wind speed remains low $\left(<1.0 \mathrm{~ms}^{-1}\right)$ with less significant monthly/seasonal variations. However, the average value of wind speed is found to be slightly lower during post-monsoon period. The predominant surface wind direction over Mohal is generally south-southwest. During the study period, relative humidity is observed highest in monsoon $(\sim 70 \%)$ and lowest in post-monsoon and winter $(\sim 61 \%)$. The monthly temperature is found to vary between $7^{\circ} \mathrm{C}$ and $26^{\circ} \mathrm{C}$. In general, the temperature is found to increase from January to August. Figure 2(e) indicates that the maximum rainfall occurs in winter months (38\% of total rainfall) and minimum in post-monsoon months ( $2 \%$ of the total rainfall). However, this rainfall pattern is in contrast to the other parts of India. The lower part of the Kullu valley starting from Aut in the south to Katrain

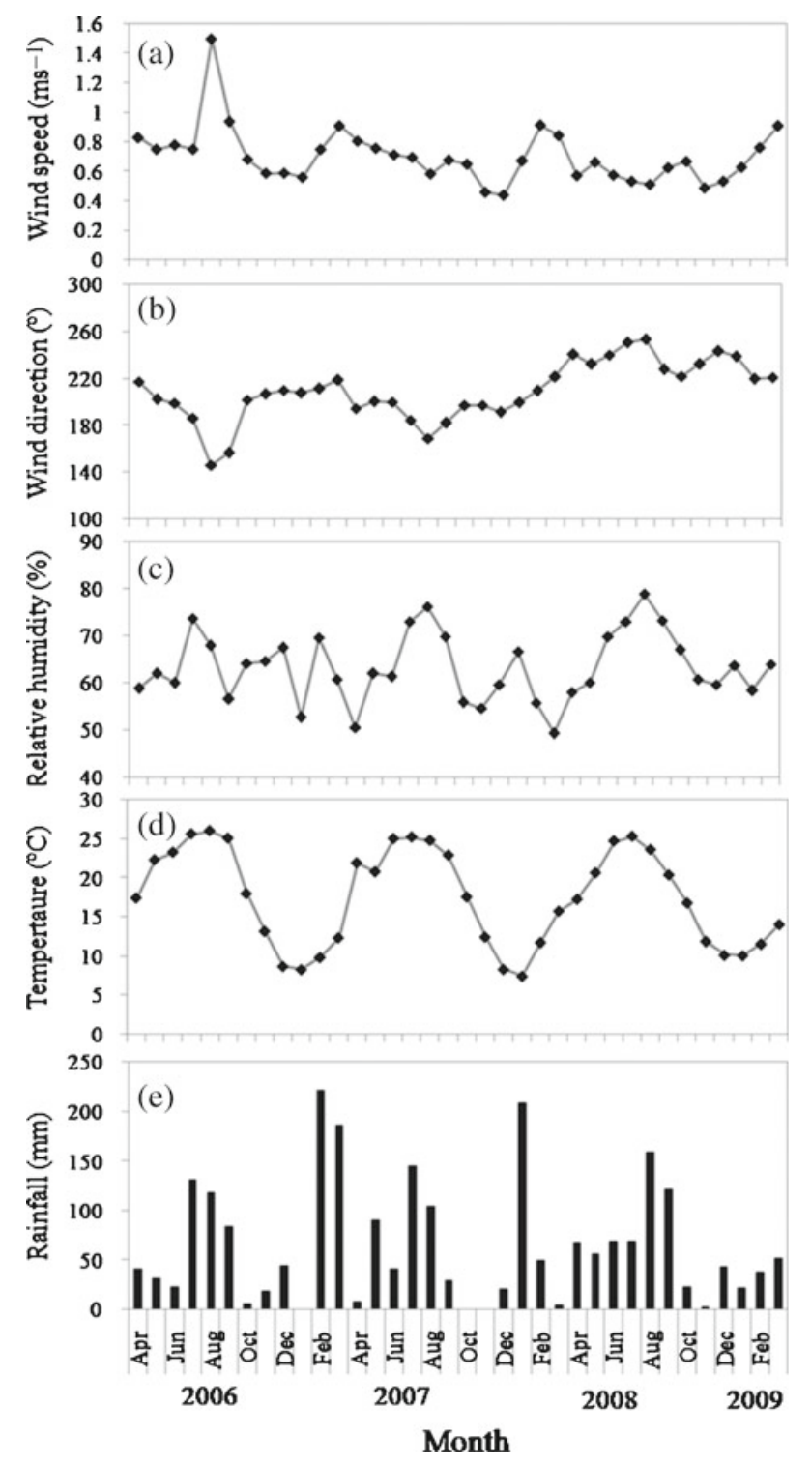

Figure 2. Monthly variation in (a) surface wind speed, (b) surface wind direction, (c) relative humidity, (d) temperature, and (e) monthly total rainfall from April 2006 to March 2009.

in the north lies in the rain shadow zone (Kuniyal et al 2009; Guleria et al 2011b) and hence receives less amount of rainfall during monsoon period as compared to winter period.

Figure 3 shows the average seasonal pattern of the prevailing winds at $700 \mathrm{hPa}$, averaged over the period 2006-2009. The map of prevailing synoptic wind vectors is obtained from the National Centers for Environmental Prediction (NCEP) reanalysis website (http://www.cdc.noaa.gov). Figure 3 shows that the wind pattern at $700 \mathrm{hPa}$ over Mohal is calm and is of mixed origins. During premonsoon, the north-westerly wind flows towards Mohal with a velocity of about $3 \mathrm{~ms}^{-1}$. In monsoon, the prevailing winds flow towards the present 

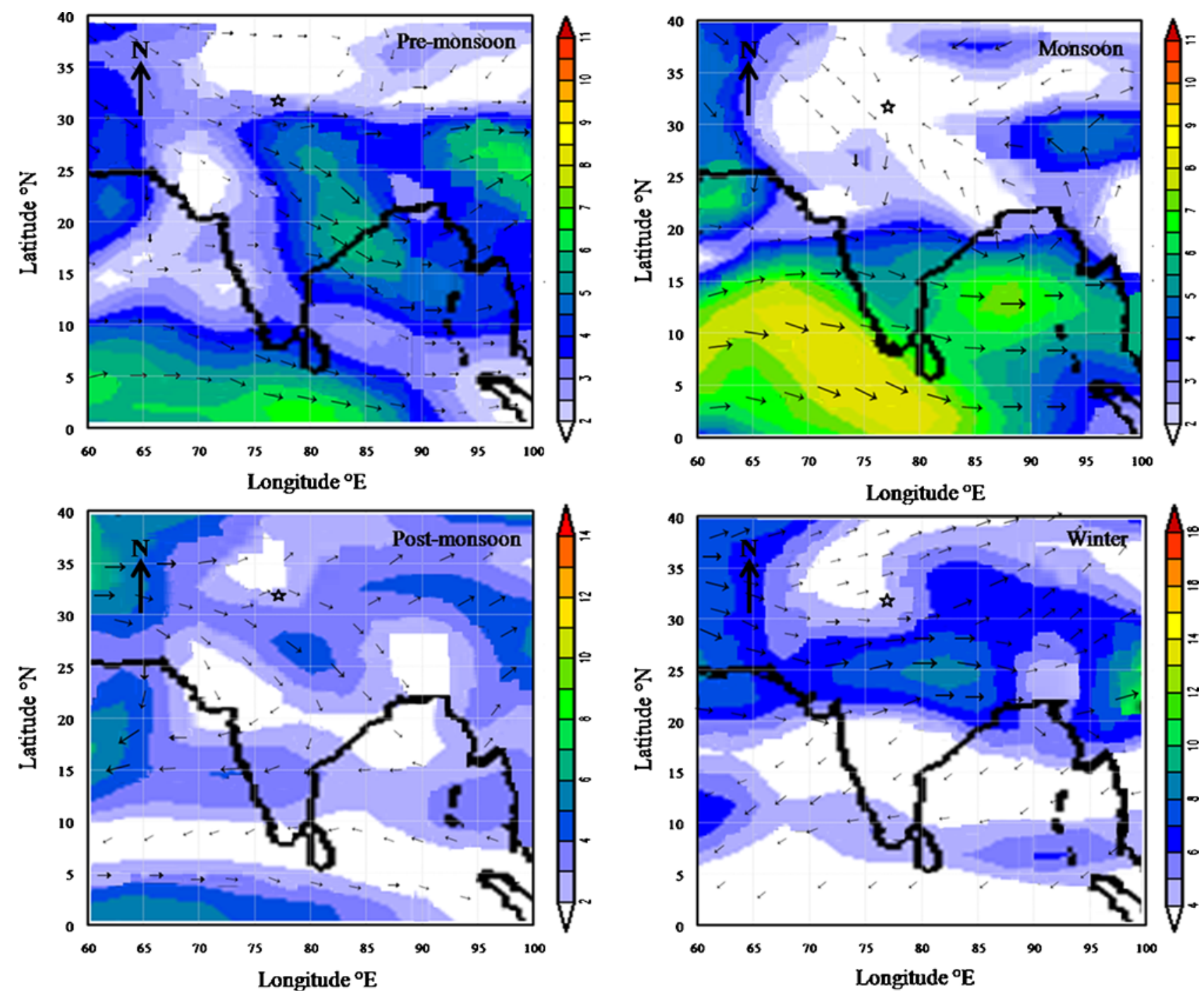

Figure 3. NCEP re-analysis mean vector wind patterns at $700 \mathrm{hPa}$ level over the Indian region for pre-monsoon (AprilJuly), monsoon (August-September), post-monsoon (October-November) and winter (December-March) seasons during the measurement period (April 2006-March 2009). The shades represent the magnitudes of wind in ms ${ }^{-1}$, the arrows show direction and the star denotes the location of Mohal.

experimental site from the northwestern part and the Bay of Bengal. Whereas in post-monsoon and winter, the westerly winds seem to be dominant with a velocity of about $3 \mathrm{~ms}^{-1}$.

\section{Instrumentation, data and analysis}

\subsection{AOD measurement}

The measurements of spectral AOD were carried out at Mohal for the period 'April 2006 to March 2009' using multi-wavelength radiometer (MWR). The MWR instrument is designed and developed at Space Physics Laboratory, Vikram Sarabhai Space Centre, Thiruvananthapuram (Moorthy et al 1999). The MWR having a field of view $\sim 2^{\circ}$, takes measurements of the spectral extinction of ground reaching solar flux as a function of solar zenith angle at 10 wavelengths, centred at $0.38,0.4$, $0.45,0.5,0.6,0.65,0.75,0.85,0.935$ and $1.025 \mu \mathrm{m}$ (Moorthy et al 1999). The MWR works on the principle of filter wheel radiometer as described by Shaw et al (1973) and was operated on all cloud-free days. During the measurement period, the prevailing weather conditions in majority of the days were cloudy. This limits the availability of MWR data. There were only 181 data points over the entire study period as the measurements were restricted to clear sky days. However, Mohal region received maximum amount of rainfall in winter months of 2008, but the MWR measurements could become possible due to less number of cloudy days as compared to June--July 2008. The 
raw data obtained through MWR is further analysed to obtain AOD following Langley techniques (Shaw et al 1973). In analysing the MWR data, the data collected during the forenoon and afternoon parts of the day is considered as a single dataset and the average spectral AOD is retrieved following Langley technique (Gogoi et al 2008, 2009). A detailed description of the MWR instrument and data analysis techniques have been published elsewhere (Moorthy et al 1999, 2001; Sagar et al 2004; Bhuyan et al 2005; Gogoi et al 2008).

Long-term temporal stability of the Langley intercept, corrected for the daily variation of the Sun-Earth distance is used as an indirect calibration of the instrument. Since Langley intercept remains invariant over years and any change in zero airmass intercept should arise from variations in the MWR parameters. Errors in the AOD measurements can arise from contribution of forward scattering to the measured flux; airmass calculation, deviation in the calibration coefficient, and in estimation of the optical depth by molecular scattering and absorption. Estimates have shown that if these errors are added, there may have the maximum uncertainty of $\sim 0.03$ (Gogoi et al 2008). For more details about the errors involved in MWRmeasured AOD, see earlier papers, e.g., Moorthy et al (1999, 2001), Sagar et al (2004), Bhuyan et al (2005) and Gogoi et al (2008).

\subsection{Angström exponent $(\alpha)$ and turbidity coefficient $(\beta)$}

Ångström proposed an empirical formula to approximate the spectral dependence of atmospheric extinction caused by aerosols. Spectral AOD contains information pertaining to size distribution used to compute $\alpha$ and $\beta$ using empirical formula which is famously known as the Ångström Power Law (Ångström 1961).

$$
\tau_{p \lambda}=\beta \lambda^{-\alpha},
$$

where wavelength $(\lambda)$ is expressed in $\mu \mathrm{m}$. The logarithmic scale of equation (1) yields a straight line as:

$$
\ln \tau_{p \lambda}=\ln \beta-\alpha \ln \lambda .
$$

The plots of $\ln \tau_{p \lambda}$ versus $\ln \lambda$, yield a straight line of slope $-\alpha$ and intercept $\ln \beta$. The validity of the Ångström Power Law is stated after Junge Power Law (Junge 1955) for a limited range of particles, where significant extinction takes place and the spectral variation of the refractive index does not impose any significant variations on the Mie extinction factor (Kaskaoutis et al 2006). For more details of $\alpha$ and $\beta$ and its computation techniques, see Bhuyan et al (2005); Gogoi et al (2008) and Sharma et al (2011).

\subsection{Second order polynomial fit}

Due to varied sources and their formation mechanism, the aerosol size distribution in the atmosphere is rarely uni-modal. When it is multi-modal, the wavelength dependence of AOD does not follow Ångström Power Law (Eck et al 1999). Therefore, departure from the linear behaviour of $\ln \tau_{p \lambda}$ versus $\ln \lambda$ data is expected. The second order polynomial fit to examine the curvature in the AOD spectra can be followed to estimate the error for each spectral AOD dataset. The second order polynomial fit to examine the curvature in the AOD spectra is expressed as:

$$
\ln \tau_{p \lambda}=a_{2}(\ln \lambda)^{2}+a_{1} \ln \lambda+a_{o},
$$

where $a_{1}, a_{2}$ and $a_{o}$ are constants. The coefficient $a_{2}$ represents the curvature observed in the spectral distribution of AOD when $\ln \tau_{p \lambda}$ is plotted against $\ln \lambda$. The curvature is an indicator of the aerosol particle size. The positive curvature indicates that the aerosol size distribution is dominated by coarse mode aerosols, while negative curvatures with fine mode aerosols (Eck et al 1999; Schuster et al 2006). Near to zero values are indicative of bi-modal aerosol distributions with similar contribution of coarse mode and fine mode aerosols (Eck et al 1999; Schuster et al 2006).

\section{Results and discussion}

\subsection{Seasonal variations in $A O D$ and Angström parameters}

The seasonal variations in AOD averaged over the period April 2006 to March 2009 obtained at 0.38, 0.5 and $1.025 \mu \mathrm{m}$ wavelengths are shown in figure 4(a). The vertical bars represent the standard deviation from the mean of the observations. We chose these wavelengths for the analysis because these are representative of the ultra violet, visible and near-infrared wavelength spectrum, where the effect of scattering due to aerosols of different size can be differentiated (Schuster et al 2006). It is also made clear that the AOD in the short wavelength region are more influenced by fine mode aerosols, while in the longer wavelengths by coarse mode aerosols (Kedia and Ramachandran 2010). The variation in AOD in all seasons is found to be wavelength-dependent. The standard deviations of AODs are large during the premonsoon and monsoon, which indicate higher dayto-day variability in the characteristics of aerosols 

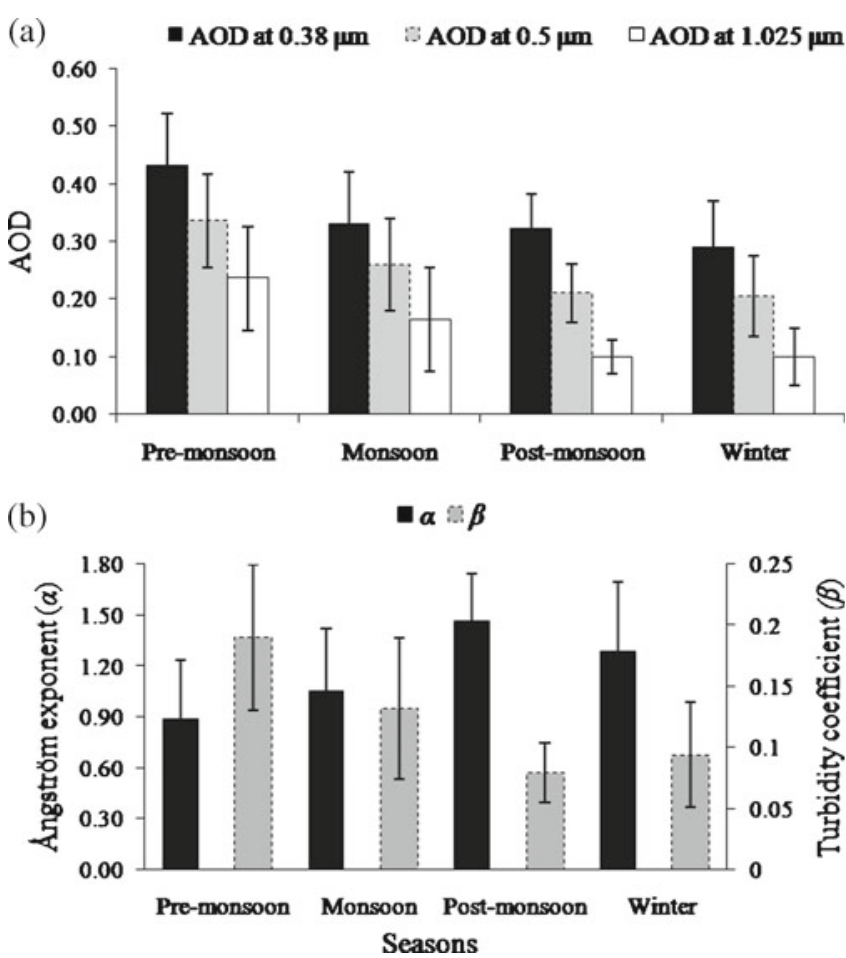

Figure 4. Seasonal variations in (a) AOD obtained at 0.38, 0.5 and $1.025 \mu \mathrm{m}$ wavelengths and (b) $\alpha$ and $\beta$ estimated from the linear fit of spectral AOD in the spectral band of $0.38-1.025 \mu \mathrm{m}$. The vertical bar represents the standard deviations from the mean of the observations.

(Holben et al 2001). The daily average (mean \pm standard deviation) AOD at 0.38, 0.5 and $1.025 \mu \mathrm{m}$ wavelengths for the entire study period is obtained as $0.33 \pm 0.10,0.24 \pm 0.08$ and $0.14 \pm 0.07$, respectively. The seasonal highest AOD at $0.38,0.5$ and $1.025 \mu \mathrm{m}$ wavelengths in pre-monsoon are obtained as $0.43 \pm 0.09,0.34 \pm 0.08$, and $0.24 \pm 0.09$, respectively. This is due to enhanced loading of dust aerosols, which are transported from the desert regions (e.g., Sahara Desert, Thar Desert, etc.) (Kuniyal et al 2009; Guleria et al 2011a, 2011b, 2012). The seasonal lowest AOD at 0.38 and $0.5 \mu \mathrm{m}$ wavelengths are obtained as $0.29 \pm 0.08$ and $0.20 \pm$ 0.07 at $0.5 \mu \mathrm{m}$ in winter, whereas AOD at $1.025 \mu \mathrm{m}$ wavelength is obtained as $0.09 \pm 0.03$ in postmonsoon. The AOD at $0.38,0.5$ and $1.025 \mu \mathrm{m}$ wavelengths decreased from pre-monsoon to winter with notable reduction of around $33 \%, 41 \%$ and $58 \%$, respectively. The sharp change in AOD at longer wavelengths indicates that the coarse mode aerosols decreased significantly from pre-monsoon to winter.

The seasonal variations in $\alpha$ and $\beta$ averaged over the period April 2006 to March 2009 is estimated from the linear fit of spectral AOD in the spectral band 0.38-1.025 $\mu \mathrm{m}$ (figure 4b). From figure $4(\mathrm{a}, \mathrm{b})$, it is known that during pre-monsoon, large AOD values are associated with small $\alpha$ values. This indicates that the relative concentration of coarse mode aerosols is higher than fine mode aerosols. Kuniyal et al (2009) and Guleria et al (2011a, 2011b, 2012) conducted the study over Mohal on aerosol transport using the back trajectories in conjunction with Cloud-Aerosol Lidar and Infrared Pathfinder Satellite Observations (CALIPSO) analysis. Their studies report that during pre-monsoon, the AOD at Mohal is mostly affected due to the transport of dust aerosols from the desert regions such as Sahara Desert, Thar Desert, etc. This could be the cause of a large concentration of coarse mode aerosols over Mohal. During post-monsoon, small AOD values are associated with large $\alpha$ values. This indicates that during post-monsoon, the contribution of fine mode aerosols in the atmosphere is relatively more than coarse mode aerosols. Guleria et al (2011b, 2012) report that during post-monsoon, AOD at Mohal is affected by the transport of smoke aerosols from the plains of India. This could be one of the major causes for the accumulation of more fine aerosols over Mohal. The seasonal mean values show that the $\beta$ decreased from premonsoon to post-monsoon with notable reduction of $58 \%$. Whereas the $\alpha$ increased from pre-monsoon to post-monsoon with a notable increase around $67 \%$. The daily average values of $\alpha$ and $\beta$ for the entire study period are obtained as $1.20 \pm 0.41$ and $0.12 \pm 0.06$, respectively.

\subsection{Errors and uncertainties in the retrieval of Angström parameters}

Kaskaoutis and Kambezidis (2006) reported that the computation of Angström parameters $(\alpha, \beta)$ using least square method (linear regression fit) is not applicable for all atmospheric conditions and locations, because this method is least wavelengthdependent. Mohal experimental site is characterized by natural and anthropogenic aerosols which show distinct seasonal characteristics over the region (Guleria et al 2011b). The pre-monsoon season is a key period when dust aerosol loading peaks over Mohal (Kuniyal et al 2009; Guleria et al 2011a, 2011b). The prevailing westerly airmass transports dust aerosols originating from the western desert regions (Kuniyal et al 2009; Guleria et al 2011a, 2011b). During post-monsoon season, the transport of anthropogenic aerosols from the plains of India and polluted continent of Pakistan and Afghanistan cause increase in aerosol loading over the Mohal region (Guleria et al 2011b). Local sources such as fuel wood burning and seasonal forest fires are also the main contributors to the building up of aerosol layer over Mohal. Thus, the 

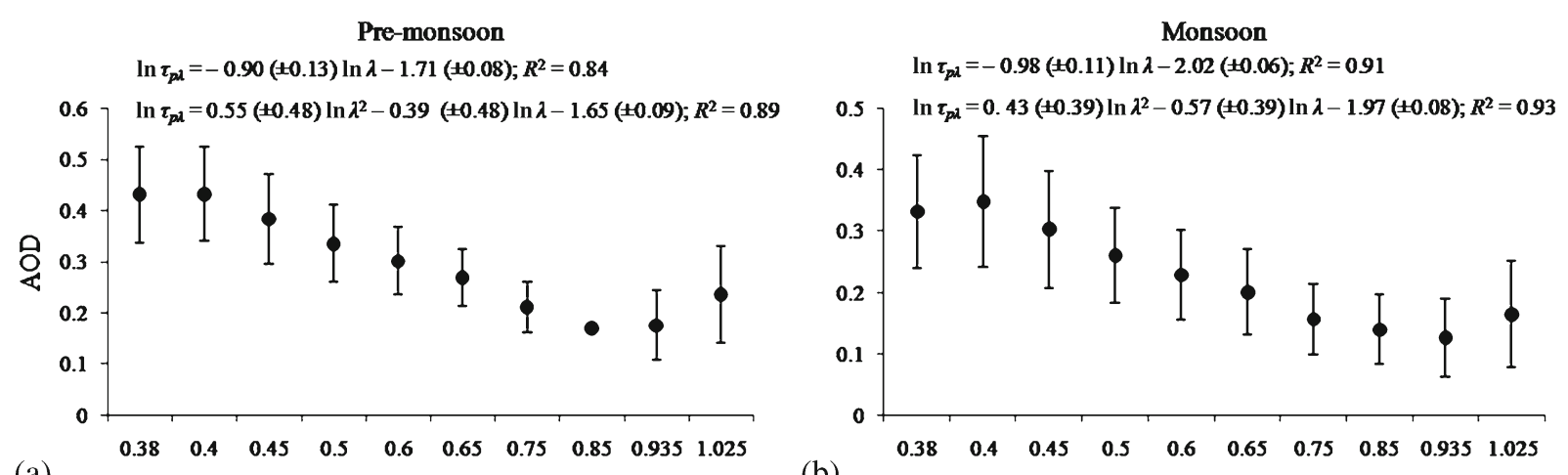

(a)

(b)
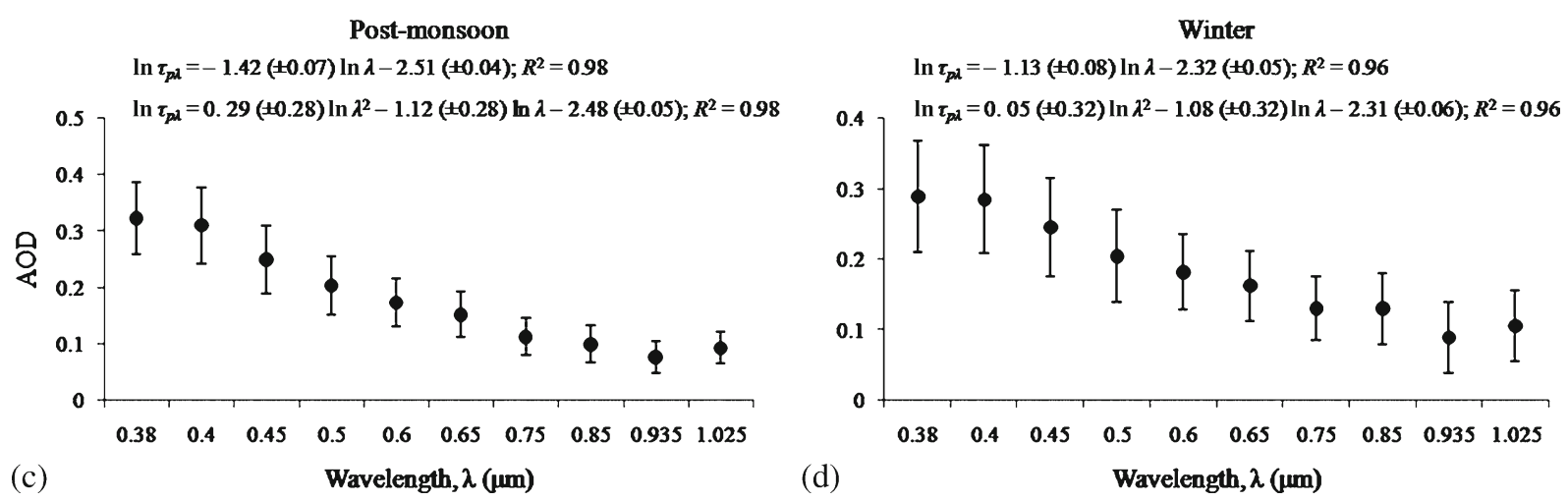

Figure 5. Seasonal variations in spectral AOD in spectral band of $0.38-1.025 \mu \mathrm{m}$. The vertical bar represents the standard deviations from the mean of the observations. The linear and the second order polynomial fit equations for each season are shown.

Table 1. Seasonal average (mean \pm error) linear fit parameters and second order polynomial fit coefficients computed in the spectral band of 0.38-1.025 $\mu \mathrm{m}$ during April 2006 to March 2009.

\begin{tabular}{|c|c|c|c|c|c|c|c|}
\hline \multirow[b]{2}{*}{ Season } & \multicolumn{3}{|c|}{ Linear fit parameters } & \multicolumn{4}{|c|}{ Second order polynomial fits coefficients } \\
\hline & $\alpha \pm$ error & Intercept \pm error & $R^{2}$ & $a_{2} \pm$ error & $a_{1} \pm$ error & $a_{o} \pm$ error & $\overline{R^{2}}$ \\
\hline Pre-monsoon & $0.90 \pm 0.13$ & $1.71 \pm 0.08$ & 0.84 & $+0.55 \pm 0.48$ & $-0.39 \pm 0.49$ & $-1.65 \pm 0.09$ & 0.89 \\
\hline Monsoon & $0.98 \pm 0.11$ & $2.02 \pm 0.06$ & 0.91 & $+0.43 \pm 0.39$ & $-0.57 \pm 0.39$ & $-1.97 \pm 0.08$ & 0.93 \\
\hline Post-monsoon & $1.42 \pm 0.07$ & $2.51 \pm 0.04$ & 0.98 & $+0.29 \pm 0.28$ & $-1.12 \pm 0.28$ & $-2.48 \pm 0.05$ & 0.98 \\
\hline Winter & $1.13 \pm 0.08$ & $2.32 \pm 0.05$ & 0.96 & $+0.05 \pm 0.32$ & $-1.08 \pm 0.32$ & $-2.31 \pm 0.06$ & 0.96 \\
\hline
\end{tabular}

present study is conducted using the application of second order polynomial fit in order to understand the applicability of Ångström Power Law. The seasonal variations in spectral AOD in the spectral band of $0.38-1.025 \mu \mathrm{m}$ are shown in figure 5 . The seasonal average (mean \pm error) values of linear fit parameters and second order polynomial fit coefficients computed in the spectral band of $0.38-1.025 \mu \mathrm{m}$ are shown in table 1. From this table, it is clear that during pre-monsoon, the linear and second order polynomial fits have exhibited large uncertainties. However, the linear regression fit method $\left(R^{2}=0.84\right)$ is found to be least wavelength-dependent compared to second order polynomial fit $\left(R^{2}=0.89\right)$. The coefficient of determinant $\left(R^{2}\right)$ is a measure to know how well the regression line approximates the real data points and provides information about the effectiveness of the linear and second order polynomial fits (Kedia and Ramachandran 2009). During monsoon, the linear and second order polynomial fits have also exhibited large uncertainties, but they are relatively low compared to pre-monsoon. The linear regression fit method $\left(R^{2}=0.91\right)$ is found to be least wavelength-dependent compared to second order polynomial fit $\left(R^{2}=0.93\right)$. The large values of positive $a_{2}$ and small values of $\alpha$ indicate that during pre-monsoon and monsoon, the coarse mode aerosols are dominant. During post-monsoon and winter, both the fits have exhibited low uncertainties with strong dependency on wavelength (see table 1 ). The small values of positive $a_{2}$ and large values of $\alpha$ indicate that during post-monsoon and winter, the fine mode aerosols are dominant. From 
the results of this study, it is found that the linear and second order polynomial fits have exhibited higher accuracy during post-monsoon and winter in comparison to pre-monsoon and monsoon, when significant uncertainties and errors in the retrieved parameters, i.e., $\alpha, a_{1}$ and $a_{2}$ occurred in close association with coarse mode aerosols. But, the use of least square method is found least wavelengthdependent compared to second order polynomial fits.

Earlier studies reported that computation of $\alpha$ using least square method is least wavelengthdependent and is not appropriate for all seasons or the days where the size distribution is dominated by significant presence of coarse mode aerosols (Eck et al 1999; Reid et al 1999; Schuster et al 2006; Kaskaoutis et al 2007). High value of $R^{2}$ means a good agreement between the linear and second order polynomial fits indicating that aerosol size distribution is dominated by significant presence of fine mode aerosols (Kedia and Ramachandran 2009). So, an attempt is made to draw a plot between $R^{2}$ and $\alpha$ computed in the spectral band of $0.38-1.025 \mu \mathrm{m}$ (figure 6 ). From correlation plot, it is noticed that at $\alpha<1.0$, second order polynomial fit in $61 \%$ cases has shown wavelength dependent behaviour with $R^{2}>90$, whereas in case of linear fit it is $40 \%$. At $\alpha>1.0$, second order polynomial fit in $98 \%$ cases has shown wavelength dependent behaviour with $R^{2}>90$, whereas in case of linear fit it is $84 \%$. Therefore, this study signifies that the computation of $\alpha$ and $\beta$ using least square method is least wavelength-dependent. So, it is not appropriate for all the seasons or days where the aerosol size distribution is dominated by significant concentrations of coarse mode aerosol.

A detailed analysis is carried out to estimate the errors and uncertainties of the second order polynomial fit to the spectral AOD. The reason of the errors arising in the estimation of $a_{1}$ and $a_{2}$ is worked out. The errors in $a_{1}$ and $a_{2}$ show the

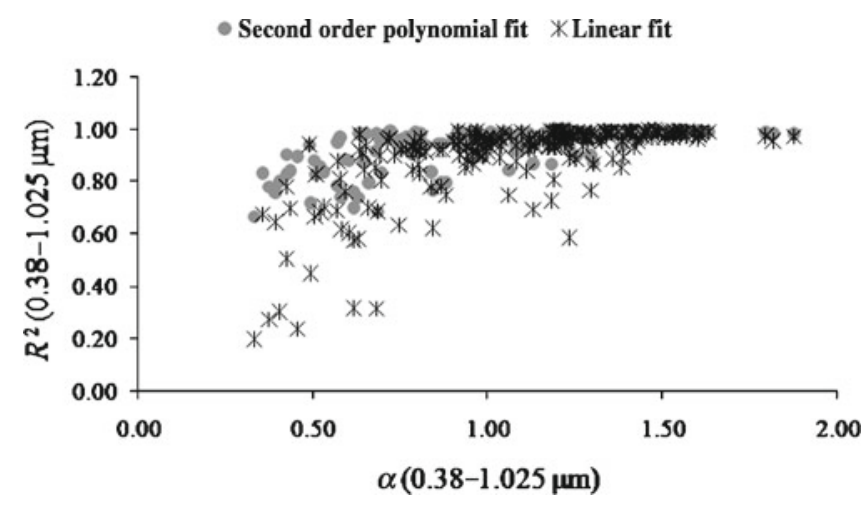

Figure 6. Correlation between the coefficients of determinant $\left(R^{2}\right)$ and $\alpha$ for spectral band of $0.38-1.025 \mu \mathrm{m}$. relative skill of the second order polynomial fit in simulating the AOD spectral distribution and express the scatter of the AOD around the polynomial curve (Schuster et al 2006; Kaskaoutis et al 2007). Figure $7(\mathrm{a}, \mathrm{b})$ shows the correlation of the errors in $a_{1}$ and $a_{2}$ evaluated in spectral bands of $0.38-1.025 \mu \mathrm{m}$ and $0.38-0.75 \mu \mathrm{m}$ with AOD at $0.5 \mu \mathrm{m}$. From the plots, it is found that error $a_{1}$ and error $a_{2}$ decreased with AOD. However, despite the fact that error $a_{1}$ and error $a_{2}$ indicate an exponential decrease in spectral band of $0.38-0.75 \mu \mathrm{m}$ and in spectral band of $0.38-1.025 \mu \mathrm{m}$ seems to be rather neutral. A large number of errors in the computed coefficients are observed for low AOD $\leq 0.25$ which themselves exhibit large variations. Nevertheless, as the AOD increases (AOD $>0.35)$, the error in the estimate decreases dramatically. Schuster et al (2006) reported that $\alpha=a_{2}-a_{1}$, therefore large errors in $a_{1}$ and $a_{2}$ lead to a larger uncertainty in the linear fit. AOD values at $0.5 \mu \mathrm{m}$ in $63 \%$ cases are $\leq 0.25$. This reveals that a larger uncertainty occurred in retrieval of $\alpha$ in close association with low AOD values. Kaskaoutis et al (2006) reported that this feature is common in sunphotometric measurements and is attributed to the higher variability of the spectral AOD.

\subsection{Curvatures in AOD spectra}

To verify the validity of relation $\alpha=a_{2}-a_{1}$, the correlation between $\alpha$ and $a_{2}-a_{1}$ in different spectral bands is shown in figure $8(\mathrm{a}, \mathrm{b})$. The data points lying on 1:1 line or closely around it are found to confirm the validity of the relation $\alpha=a_{2}-a_{1}$. The linear fit and second order polynomial fit computed in the wavelength interval $0.38-1.025 \mu \mathrm{m}$ are found in good agreement with root mean square deviation (RMSD), mean absolute bias deviation (MABD) and correlation coefficient of $0.08,0.01$ and 0.98 for the daily observations, respectively having intercepts close to zero. While, in the wavelength interval 0.38-0.75, the RMSD, MABD and correlation coefficients for daily observations are obtained as $0.31,0.14$ and 0.74 , respectively with the intercepts 0.39 . There is almost no systematic overestimation of the $a_{2}-a_{1}$ against $\alpha$ (figure $8 \mathrm{a}$ ), while it seems to be present in figure $8(\mathrm{~b})$ at $\alpha<1.5$. These agreements provide the validation of the linear and polynomial fit equations computed in the spectral band of $0.38-1.025 \mu \mathrm{m}$. Whereas in the spectral band of $0.38-0.75 \mu \mathrm{m}$, the linear and polynomial fit-derived parameters are not found in good agreement and the retrieved parameters are found to discard the validity of the relation $\alpha=a_{2}-a_{1}$. From the analysis, it is found that as the wavelength region shifts towards 

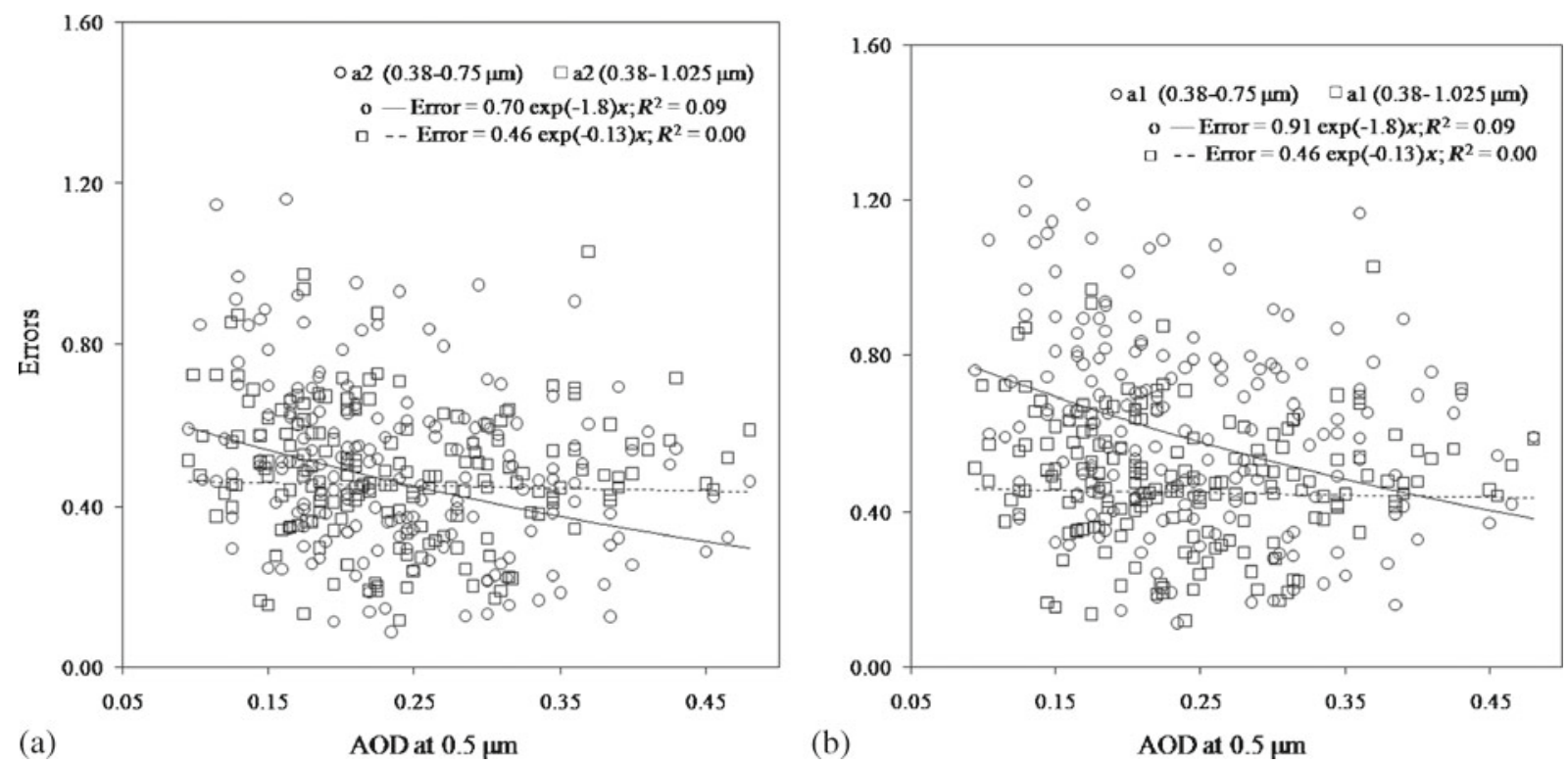

Figure 7. Correlation of the errors in $a_{2}$ and $a_{1}$ obtained from the polynomial fit of the $\ln \tau_{p \lambda}$ versus $\ln \lambda$ in the two spectral bands with the AOD at $0.5 \mu \mathrm{m}$.
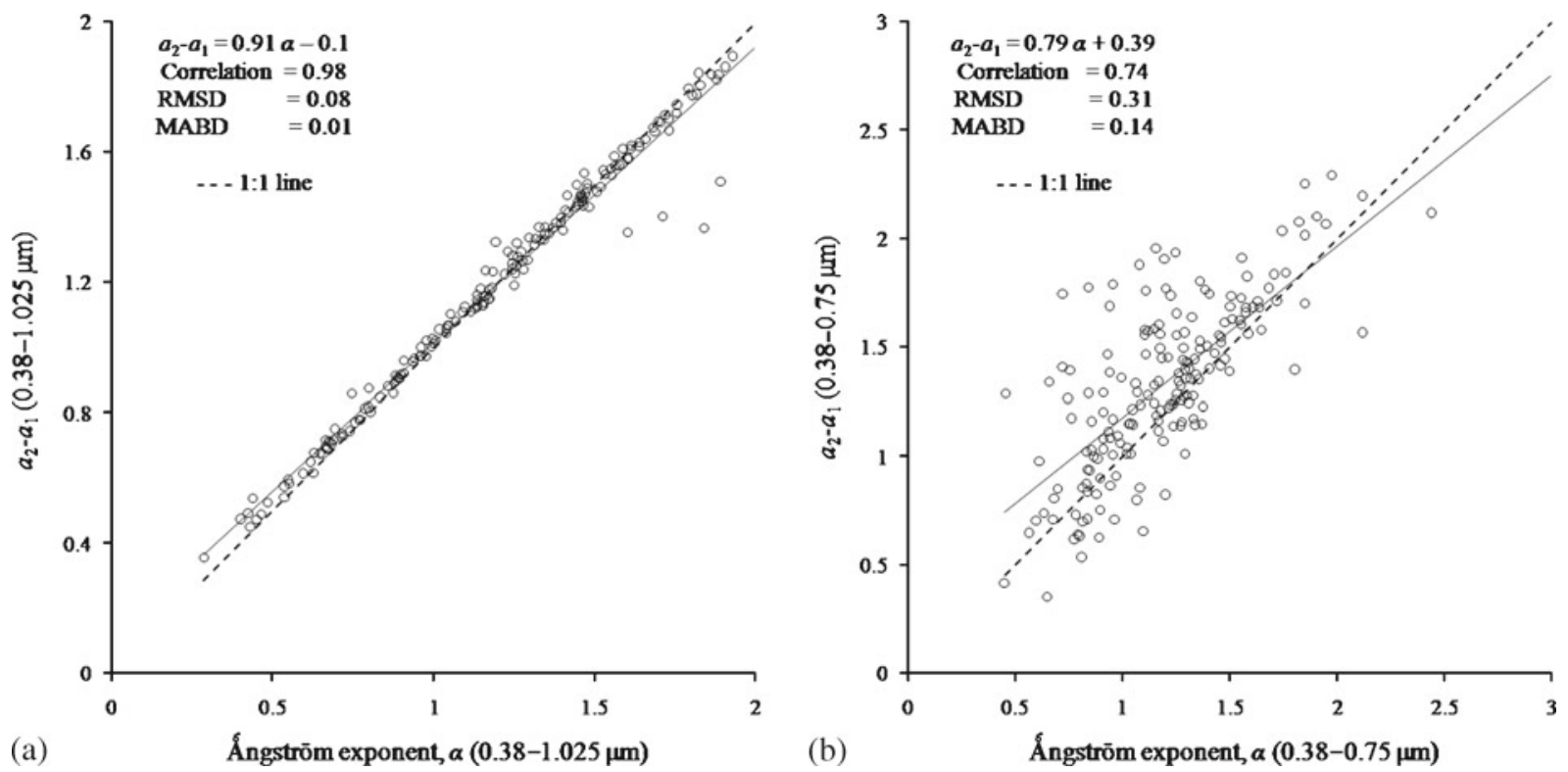

Figure 8. Correlation between $a_{2}-a_{1}$ and $\alpha$ for (a) spectral band of $0.38-1.025 \mu \mathrm{m}$ and (b) spectral band of $0.38-0.75 \mu \mathrm{m}$. The dotted black lines represent the 1:1 line and the dark line, the linear equation.

shorter wavelengths, the use of least square is not appropriate for the retrieval of Angström parameters. Therefore, this study indicates that there is a need to look into the curvature effect in retrieval of size parameter using Ångström Power Law at shorter wavelength spectrum. This feature is further investigated during some important cases. A typical example of 30 May 2008 is shown in figure $9(\mathrm{a}, \mathrm{b})$ whereas the wavelength region used for $\alpha$ determination shifts towards shorter wavelengths, higher $\alpha$ value is observed. The positive curvature in the $\ln \tau_{p \lambda}$ versus $\ln \lambda$ relationship indicates significant fraction of coarse mode aerosols. The linear and second order polynomial fit equations computed in different spectral bands are obtained as:

$$
\begin{aligned}
\ln \tau_{p \lambda} & =-0.66( \pm 0.15) \ln \lambda-1.75( \pm 0.09) ; \\
R^{2} & =0.71 ;(0.38-1.025 \mu \mathrm{m})
\end{aligned}
$$



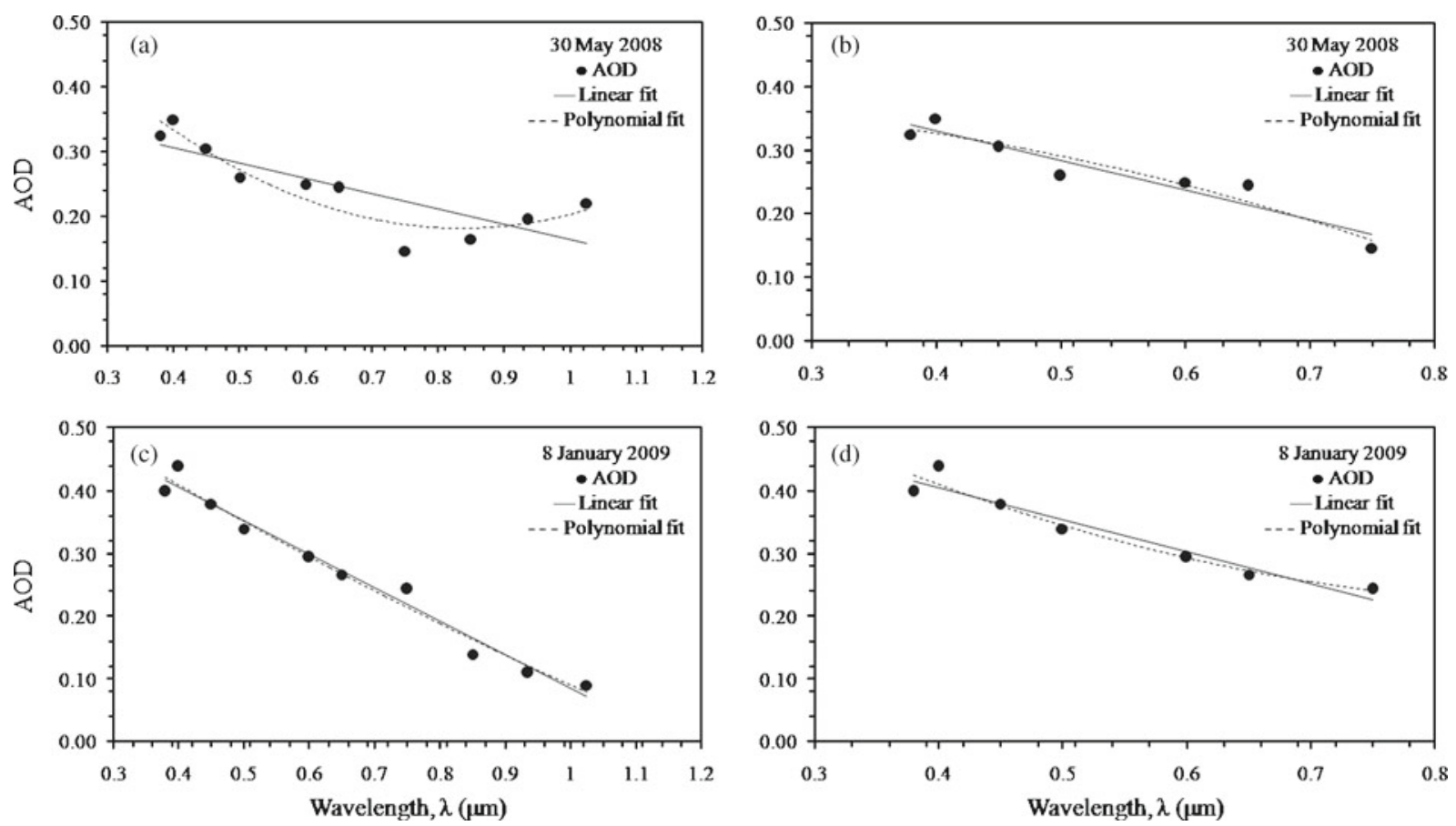

Figure 9. Typical examples of spectral variation in AOD versus wavelength. The linear and the second order polynomial fits for each case are shown in the illustration.

$$
\begin{aligned}
\ln \tau_{p \lambda}= & 0.91( \pm 0.49) \ln \lambda^{2} \\
& +0.21( \pm 0.49) \ln \lambda-1.64( \pm 0.10) ; \\
R^{2}= & 0.81 ;(0.38-1.025 \mu \mathrm{m}) \\
\ln \tau_{p \lambda}= & -1.01( \pm 0.17) \ln \lambda-2.00( \pm 0.12) ; \\
R^{2}= & 0.88 ;(0.38-0.75 \mu \mathrm{m}) \\
\ln \tau_{p \lambda}= & -1.22( \pm 0.84) \ln \lambda^{2} \\
& -2.57( \pm 1.08) \ln \lambda-2.43( \pm 0.30) ; \\
R^{2}= & 0.92 ;(0.38-0.75 \mu \mathrm{m})
\end{aligned}
$$

The large value of positive $a_{2}$ and small value of $\alpha$ (see equations 4 and 5) indicate that on 30 May 2008 , the AOD spectra is dominated by coarse mode aerosols. When the wavelength region shifts towards shorter spectral band of $0.38-0.75 \mu \mathrm{m}$ (figure $9 \mathrm{~b}$ ), the large value of negative $a_{2}$ and large value of $\alpha$ (see equations 6 and 7) indicate that on 30 May 2008, the AOD spectra is dominated by fine mode aerosols. The $\alpha$ value is found to change from 0.66 to 1.01 when the wavelength region used for its determination shifts from longer wavelengths $(0.38-1.025 \mu \mathrm{m})$ towards shorter wavelengths $(0.38-0.75 \mu \mathrm{m})$. A typical example of 8 January 2009 is shown in figure $9(\mathrm{c}, \mathrm{d})$, whereas the wavelength region used for $\alpha$ determination shifts towards shorter wavelengths, smaller $\alpha$ value is observed. The negative curvature in the $\ln \tau_{p \lambda}$ versus $\ln \lambda$ relationship indicates significant fraction of fine mode aerosols. The linear and second order polynomial fit equations computed in different spectral bands are obtained as:

$$
\begin{aligned}
\ln \tau_{p \lambda}= & -1.47( \pm 0.20) \ln \lambda-2.10( \pm 0.12) ; \\
R^{2}= & 0.87 ;(0.38-1.025 \mu \mathrm{m}) \\
\ln \tau_{p \lambda}= & -1.87( \pm 0.37) \ln \lambda^{2} \\
& -3.27( \pm 0.37) \ln \lambda-2.32( \pm 0.07) ; \\
R^{2}= & 0.97 ;(0.38-1.025 \mu \mathrm{m}) \\
\ln \tau_{p \lambda}= & -0.72( \pm 0.10) \ln \lambda-1.54( \pm 0.07) ; \\
R^{2}= & 0.91 ;(0.38-0.75 \mu \mathrm{m}) \\
\ln \tau_{p \lambda}= & -0.81( \pm 0.48) \ln \lambda^{2} \\
& -1.76( \pm 0.61) \ln \lambda-1.82( \pm 0.18) ; \\
R^{2}= & 0.95 ;(0.38-0.75 \mu \mathrm{m}) .
\end{aligned}
$$

The very large values of negative $a_{2}$ and $\alpha$ (see equations 8 and 9) indicate that on 8 January 2009, the AOD spectra is dominated by fine mode aerosols. When the wavelength region shifts towards shorter spectral band of $0.38-0.75 \mu \mathrm{m}$ (figure $9 \mathrm{~d}$ ), the small values of negative $a_{2}$ and $\alpha$ relative to equations (9) and (8), respectively indicate that on 8 January 2009, the AOD spectra 

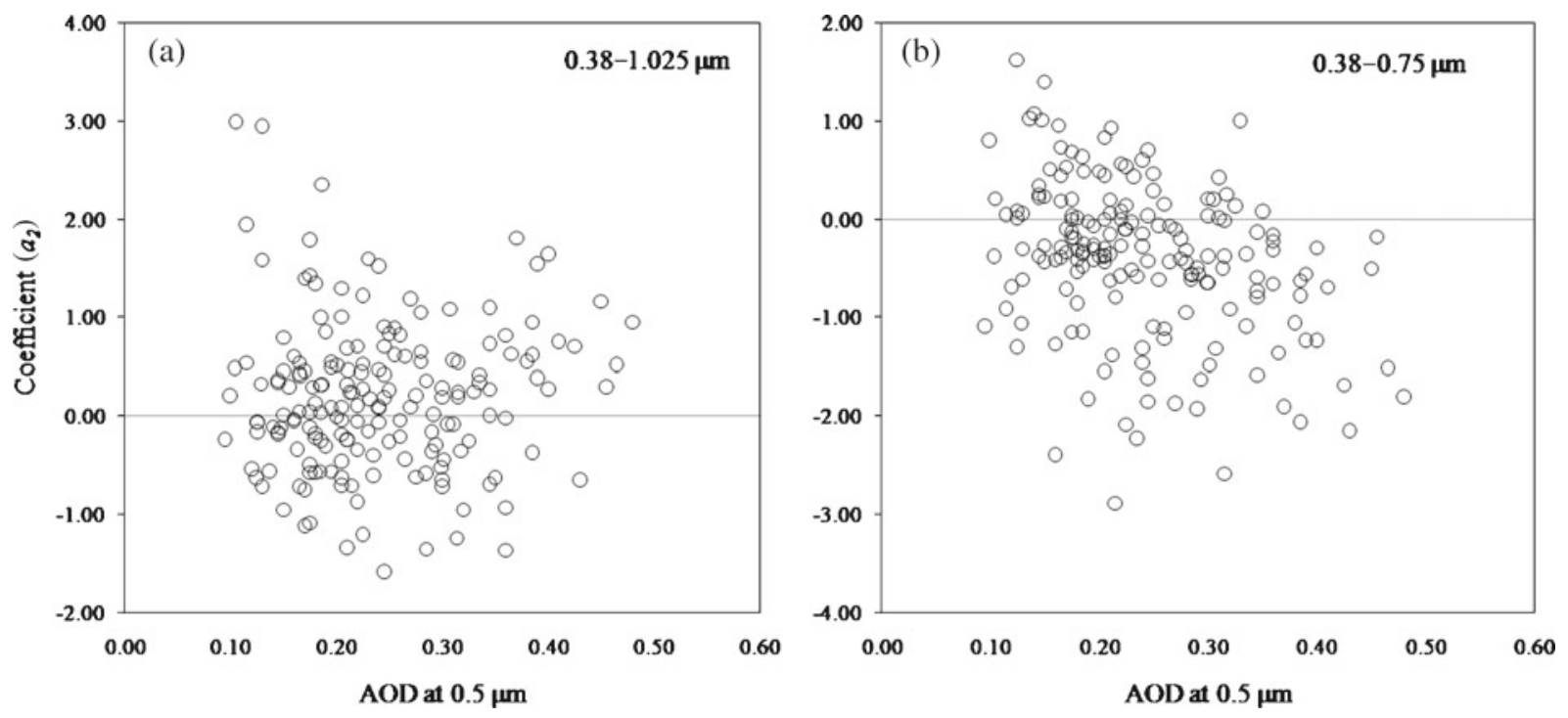

Figure 10. Scatter plot of coefficients $a_{2}$ against AOD at $0.5 \mu \mathrm{m}$.

is dominated by coarse mode aerosols. The $\alpha$ value is found to change from 1.47 to 0.72 , when the wavelength region used for its determination shifts from longer wavelengths $(0.38-1.025 \mu \mathrm{m})$ towards shorter wavelengths $(0.38-0.75 \mu \mathrm{m})$. From the above discussion, it is concluded that there is a considerable change in aerosol size distribution when the wavelength region shifts towards shorter spectral bands.

Figure 10(a, b) shows the scatter plot between polynomial coefficient $a_{2}$ and AOD at $0.5 \mu \mathrm{m}$. The correlation between $a_{2}$ and AOD at $0.5 \mu \mathrm{m}$ provides information on the atmospheric conditions under which $\alpha$ is independent from wavelengths (Sharma et al 2010). The data points lying on or around $a_{2}=$ zero line in figure $10(\mathrm{a}, \mathrm{b})$ indicate a bi-modal aerosol distribution without curvature (Schuster et al 2006; Kaskaoutis et al 2007). The negative values of $a_{2}$ suggest the presence of significant fraction of fine mode aerosols and positive values of $a_{2}$ provide the information about coarse mode aerosols. In $39 \%$ cases, the $a_{2}$ values over Mohal are obtained negative when they were computed in the spectral band $0.38-1.025 \mu \mathrm{m}$. When the wavelength region shifts towards shorter spectral band of $0.38-0.75 \mu \mathrm{m}$, the $a_{2}$ values in $70 \%$ cases are obtained negative. This study further signifies that as the wavelength region shifts towards shorter spectral band of $0.38-0.75 \mu \mathrm{m}$, a considerable change in aerosol size distribution is observed. After evaluating the results, it is observed that there is need for great effort and attention on the accuracy of AOD at shorter wavelengths. So, the use of $0.38-1.025 \mu \mathrm{m}$ spectral band for the calculation of $\alpha, a_{1}$ and $a_{2}$ values can lead to the most precise results with the lowest curvature.

\subsection{Seasonal variability in relative contribution of different mode aerosols}

Eck et al (1999) and Schuster et al (2006) reported that for the multi-modal aerosol size distribution, the polynomial coefficients $\left(a_{2}\right.$ and $\left.a_{1}\right)$ contain significant information about aerosol type. For bimodal aerosol distribution, where distributions of fine mode and coarse mode aerosols are almost with equivalent contributions, the $\alpha$ is to a close approximation of $a_{2}-a_{1}$ (i.e., $\alpha=a_{2}-a_{1}$ ) (Schuster et al 2006). For values, where $a_{2}-a_{1} \geq 2$, the AOD spectra are dominated by fine mode $(<1 \mu \mathrm{m})$

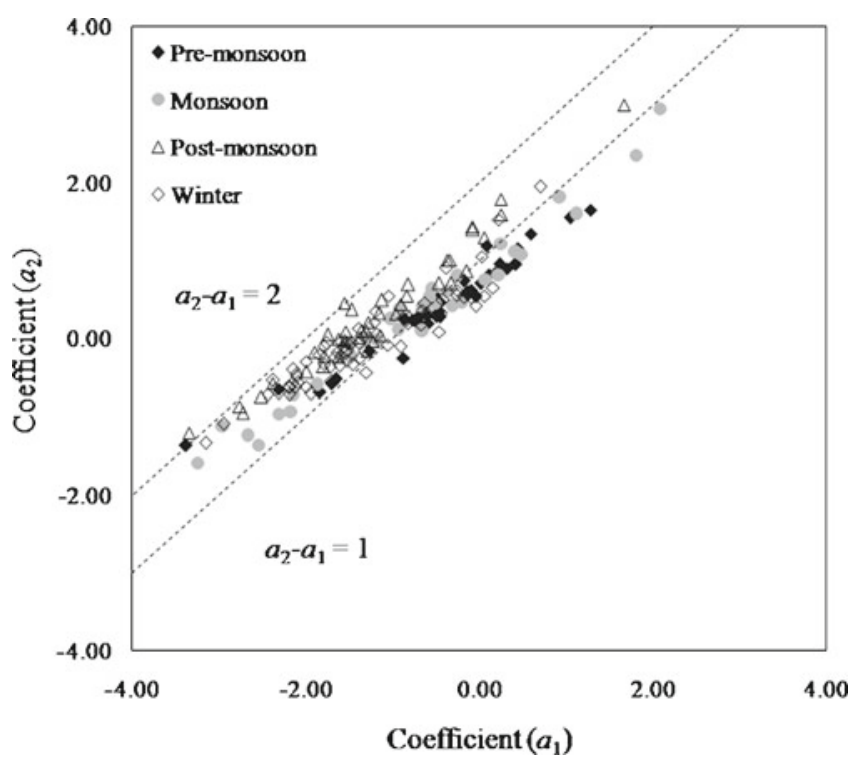

Figure 11. Seasonal variations in correlation between the coefficients $a_{2}$ and $a_{1}$ computed in the spectral range of $0.38-1.025 \mu \mathrm{m}$. Dotted lines correspond to $a_{2}-a_{1}=1$ and $a_{2}-a_{1}=2$. 


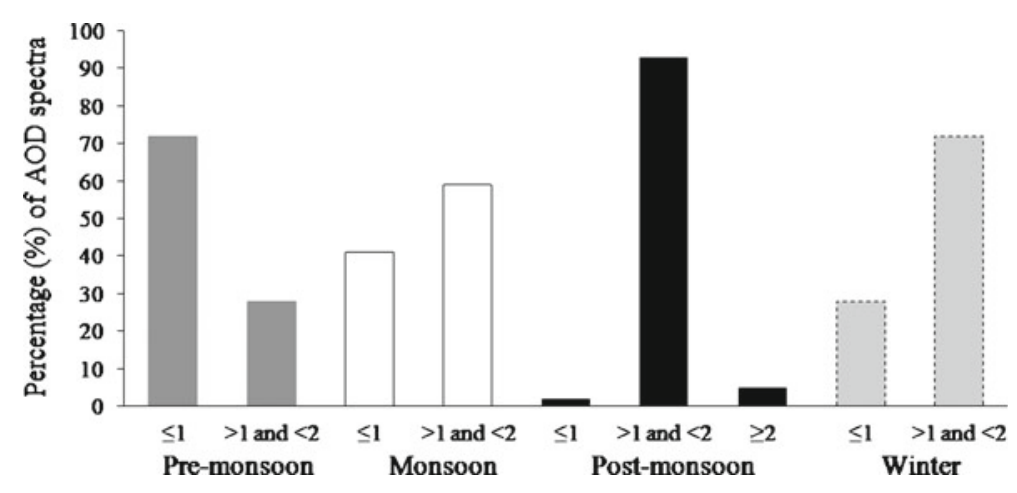

Figure 12. Percentage of AOD spectra classified on the basis of seasons $a_{2}-a_{1} \leq 1$ (coarse mode aerosols are dominant), $1<a_{2}-a_{1}<2$ (a wide range of fine mode fractions or mixture of modes), $\geq 2$ (fine mode aerosols are dominant).

aerosols, where $a_{2}-a_{1} \leq 1$, the AOD spectra are dominated by coarse mode $(>1 \mu \mathrm{m})$ aerosols. For intermediate values of $a_{2}-a_{1}$ between 1 and 2 , the AOD spectra represent a wide range of fine mode fractions or mixture of modes. To identify different modes of aerosols prevailing over Mohal, coefficients $a_{2}$ and $a_{1}$ as a function of season are plotted in figure 11. The percentage of AOD spectra having $a_{2}-a_{1} \leq 1$ and $1<a_{2}-a_{1}<2$ is found to exhibit a strong seasonal variation (figures 11 and 12). Figure 11 shows that even at same value of $a_{2}$, the value of $a_{1}$ may vary, but this feature depends on the contribution of coarse mode aerosols. Therefore, this study confirms that the use of single coefficient is not appropriate to discriminate fine mode as well as coarse mode aerosols. During premonsoon, due to dust aerosol transport from the desert prone region to Mohal (see Kuniyal et al 2009; Guleria et al 2011a, 2011b, 2012), coarse mode aerosol become dominant. This leads to a higher percentage of AOD spectra, i.e., $72 \%$ with $a_{2}-a_{1} \leq 1$ (figure 12). During monsoon, the coarse mode aerosols are dominant in $41 \%$ of AOD spectra, whereas the contribution of fine mode fractions or mixture of modes is $59 \%$ of AOD spectra. A wide range of fine mode fractions or mixture of modes is observed during post-monsoon as for $93 \%$ of the AOD spectra, $a_{2}-a_{1}$ lies between 1 and 2 . For $5 \%$ of AOD spectra, $a_{2}-a_{1} \geq 2$ indicates a strong dominance of fine mode aerosols. This large concentration of fine mode aerosol is attributed to anthropogenic aerosols, released into the atmosphere by bio-mass burning, forest fire at local levels and smoke aerosol transport from external sources (Guleria et al 2011a, 2011b, 2012). During winter, the fine mode aerosols are dominant in $72 \%$ of AOD spectra $a_{2}-a_{1}$ lies between 1 and 2 (figure 12).

This study confirmed that during post-monsoon and winter, the size distribution over Mohal computed in the spectral band of $0.38-1.025 \mu \mathrm{m}$ is found with equivalent contribution of fine mode and coarse mode aerosols. But in pre-monsoon and monsoon, aerosol size distribution is found to discard the validity of the relation, i.e., $\alpha=a_{2}-a_{1}$, which signifies the multi-modal aerosol size distribution. Therefore, this study highlights the seasonal variability in contribution of fine mode as well as coarse mode aerosols from different source origins. This study reveals that it is possible to depict the percentage contribution of different fine mode as well as coarse mode aerosols in the measured AOD spectra. Thus, the seasonal variations in aerosol characteristics from a mountain ecosystem will be useful in examining the radiative effect of aerosol at a regional level.

\section{Conclusion}

Three years measurements (April 2006 to March 2009) of seasonal variability in aerosol optical and physical characteristics were made at Mohal in the northwestern Indian Himalaya. Moreover, the appropriateness using the Ångström Power Law and second order polynomial fit for aerosols size distribution showed that the latter gives more accurate results compared to the former especially when the coarse mode aerosols dominate. In a nutshell, the major conclusions of the present study are as follows:

- The AODs on daily basis (mean \pm standard deviation) stood to be $0.33 \pm 0.10,0.24 \pm 0.08$ and $0.14 \pm 0.08$ at $0.38,0.5$ and $1.025 \mu \mathrm{m}$, respectively.

- The AOD at 0.38, 0.5 and $1.025 \mu \mathrm{m}$ have shown a reasonable decrease from pre-monsoon to winter with a significant reduction of $33 \%, 41 \%$ and $58 \%$, respectively.

- The AOD values over Mohal have shown a seasonal as well as wavelength dependent behaviour indicating an influence of local and external sources of aerosols. 
- The Ångström exponent varied significantly from pre-monsoon (April-July) to winter (DecemberMarch) indicating the dominance of anthropogenic impacts on the aerosol characteristics.

- Ångström parameters using least square method show least wavelength-dependence compared to second order polynomial fit. It is also not appropriate for the days when the size distribution is dominated by coarse mode aerosols.

- There is a considerable change in aerosol size distribution when the wavelength region shifts towards shorter spectral bands. This indicates that adequate attention is required to have greater accuracy in measuring AOD at shorter wavelengths.

- During pre-monsoon, about $72 \%$ of AOD spectra are found to be dominated by coarse mode aerosols. Whereas, during monsoon, postmonsoon and winter about 59\%, 93\% and $72 \%$ of AOD spectra are found to be dominated by a wide range of fine mode fractions or mixture of modes, respectively.

- This study highlights the seasonal variability in terms of fine as well as coarse mode aerosols from different origin sources. Thus, the data obtained on seasonal variability in aerosol characteristics ecologically from a sensitive mountain ecosystem will be useful in modelling the radiative effect of aerosols at a regional level.

\section{Acknowledgements}

The authors thank the Director of G.B. Pant Institute of Himalayan Environment and Development, Kosi-Katarmal, Almora (Uttarakhand) for providing necessary facilities. This work is carried out as a part of ARFI project under the ISRO-GBP. The authors gratefully acknowledge ISRO, Bangalore for providing financial assistance through SPL, VSSC, Thiruvanthapuram, Kerala under ARFI project. They also thank the distinguished referees for constructive and useful suggestions, which helped in improving the quality of this paper.

\section{References}

Ångström A 1961 Techniques of determining the turbidity of the atmosphere; Tellus 13 214-223.

Bhuyan P K, Gogoi M M and Moorthy K K 2005 Spectral and temporal characteristics of aerosol optical depth over a wet tropical location in northeast India; Adv. Space Res. 35 1423-1429.

Eck T F, Holben B N, Reid J S, Dubovik O, Smirnov A, O'Neill N T, Slutsker I and Kinne S 1999 Wavelength dependence of the optical depth of biomass burning, urban, and desert dust aerosols; J. Geophys. Res. 104 $31,333-31,349$.

Eck T F, Holben B N, Dubovik O, Smirnov A, Slutsker I, Lobert J M and Ramanathan V 2001 Column-integrated aerosol optical properties over the Maldives during the northeast monsoon for 1998-2000; J. Geophys. Res. 106 $28,555-28,566$.

Ganguly D, Jayaraman A and Gadhavi H 2006 Physical and optical properties of aerosols over an urban location in western India: Seasonal variabilities; J. Geophys. Res. 111 D24206, doi: 10.1029/2006JD007392.

Gogoi M M, Bhuyan P K and Moorthy K K 2008 Estimation of the effect of long-range transport on seasonal variation of aerosols over northeastern India; Ann. Geophys. 26 1365-1377.

Gogoi M M, Bhuyan P K and Moorthy K K 2009 An investigation of aerosol size distribution properties at Dibrugarh: North-eastern India; Terr. Atmos. Ocean. Sci. 20 521-533.

Guleria R P, Kuniyal J C, Rawat P S, Thakur H K, Sharma M, Sharma N L, Singh M, Chand K, Sharma P, Thakur A K, Dhyani P P and Bhuyan P K 2011a Aerosols optical properties in dynamic atmosphere in the northwestern part of the Indian Himalaya: A comparative study from ground and satellite based observations; Atmos. Res. 101 726-738.

Guleria R P, Kuniyal J C, Rawat P S, Sharma N L, Thakur H K, Dhyani P P and Singh M 2011b The assessment of aerosol optical properties over Mohal in the northwestern Indian Himalaya using satellite and ground based measurements and an influence of aerosol transport on aerosol radiative forcing; Meteorol. Atmos. Phys. 113 153-169.

Guleria R P, Kuniyal J C, Rawat P S, Thakur H K, Sharma M, Sharma N L, Dhyani P P and Singh M 2012 Validation of MODIS retrieval aerosol optical depth and an investigation on aerosol transport over Mohal in the northwestern Indian Himalaya; Int. J. Remote Sens. 33(17) 5379-5401.

Holben B N et al 2001 An emerging ground-based aerosol climatology: Aerosol optical depth from AERONET; J. Geophys. Res. 115(D11) 12,067-12,097.

IPCC 2007 Climate change 200\%: The physical science basis (Cambridge: Cambridge University Press).

Junge C E 1955 The size distribution and aging of natural aerosols as determined from electrical and optical measurements in the atmosphere; J. Meteorol. 12 13-25.

Kalapureddy M C R and Devara P C S 2010 Pre-monsoon aerosol optical properties and spatial distribution over the Arabian Sea during 2006; Atmos. Res. 95 186-196.

Kaskaoutis D G and Kambezidis H D 2006 Investigation on the wavelength dependence of the aerosol optical depth in the Athens area; Quart. J. Roy. Meteorol. Soc. 132 2217-2234.

Kaskaoutis D G, Kambezidis H D, Adamopoulos A D and Kassomenos P A 2006 Comparison between experimental data and modeling estimates of atmospheric optical depth over Athens, Greece; J. Atmos. Sol. Terr. Phys. 68 1167-1178.

Kaskaoutis D G, Kambezidis H D, Hatzianastassiou N, Kosmopoulos P G and Badarinath K V S 2007 Aerosol climatology: Dependence of the Ångström exponent on wavelength over four AERONET sites; Atmos. Chem. Phys. Discuss. 7 7347-7397.

Kaskaoutis D G, Badarinath K V S, Kharol S K, Sharma A R and Kambezidis H D 2009 Variations in the aerosol optical properties and types over the tropical urban site of Hyderabad, India; J. Geophys. Res. 114 D22204, doi: 10.1029/2009JD012423.

Kaskaoutis D G, Kalapureddy M C R, Moorthy K K, Devara P C S, Nastos P T, Kosmopoulos P G and Kambezidis H D 2010 Heterogeneity in pre-monsoon aerosol types over the Arabian Sea deduced from ship-borne measurements of spectral AODs; Atmos. Chem. Phys. 10 4893-4908. 
Kaskaoutis D G, Kharol S K, Sinha P R, Singh R P, Kambezidis H D, Sharma A R and Badarinath K V S 2011 Extremely large anthropogenic-aerosol contribution to total aerosol load over the Bay of Bengal during winter season; Atmos. Chem. Phys. 11 7097-7117.

Kedia S and Ramachandran S 2009 Variability in aerosol optical and physical characteristics over the Bay of Bengal and the Arabian Sea deduced from Ångström exponents; J. Geophys. Res. 114 D14207, doi: 10.1029/2009JD011950.

Kedia S and Ramachandran S 2010 Seasonal variations in aerosol characteristics over an urban location and a remote site in western India; Atmos. Environ. 45 21202128.

Kedia S, Ramachandran S, Kumar A and Sarin M M 2010 Spatiotemporal gradients in aerosol radiative forcing and heating rate over Bay of Bengal and Arabian Sea derived on the basis of optical, physical, and chemical properties; J. Geophys. Res. 115 D07205, doi: 10.1029/2009JD013136.

Kumar S, Devara P C S, Manoj M G and Safai P D 2011 Winter aerosol and trace gas characteristics over a highaltitude station in the Western Ghats, India; Atmósfera 24 311-328.

Kuniyal J C, Thakur A, Thakur H K, Sharma S, Pant P, Rawat P S and Moorthy K K 2009 Aerosol optical depths at Mohal-Kullu in the northwestern Indian Himalayan high altitude station during ICARB; J. Earth Syst. Sci. 118 41-48.

Meszaros E 1981 Atmospheric chemistry fundamental aspects (New York: Elsevier Scientific Publishing Company).

Moorthy K K and Satheesh S K 2000 Characteristics of aerosols over a remote island, Minicoy in the Arabian Sea: Optical properties and retrieved size characteristics; Quart. J. Roy. Meteorol. Soc. 126 81-109.

Moorthy K K, Niranjan K, Narasimhamurthy B, Agashe V V and Murthy B V K 1999 Aerosol climatology over India: ISRO-GBP MWR network and data base, ISROGBP SR-03-99, Indian Space Research Organization, Bangalore.
Moorthy K K, Saha A, Prasad B S N, Niranjan K, Jhurry D and Pillai P S 2001 Aerosol optical depth over peninsular India and adjoining oceans during the INDOEX campaigns: Spatial, temporal and spectral characteristics; J. Geophys. Res. 106 28,539-28,554.

Ramanathan V et al 2001 Indian Ocean Experiment: An integrated analysis of the climate forcing and effects of the great Indo-Asian haze; J. Geophys. Res. 106 28,37128,398 .

Reid J S, Eck T F, Christopher S A, Hobbs P V and Holben B N 1999 Use of the Angström exponent to estimate the variability of optical and physical properties of aging smoke particles in Brazil; J. Geophys. Res. 104 $27,473-27,489$.

Reist P C 1984 Introduction to aerosol science (New York: Macmillan Publishing Company).

Sagar R, Kumar B, Dumka U C, Moorthy K K and Pant P 2004 Characteristics of aerosol optical depths over Manora peak: A high altitude station in the central Himalaya; J. Geophys. Res. 109 006207, doi: 10.1029/2003JD003954.

Schuster G L, Dubovik O and Holben B N 2006 Angström exponent and bimodal aerosol size distributions; $J$. Geophys. Res. 111 D07207, doi: 10.1029/2005JD006328.

Sharma A R, Kharol S K, Badarinath K V S and Singh D 2010 Impact of agriculture crop residue burning on atmospheric aerosol loading - a study over Punjab State, India; Ann. Geophys. 28 367-379.

Sharma N L, Kuniyal J C, Singh M, Sharma M and Guleria R P 2011 Characteristics of aerosol optical depth and Ångström parameters over Mohal in the Kullu valley of northwest Himalayan region, India; Acta Geophys. 59(2) 334-360.

Shaw G E, Reagan J A and Herman B M 1973 Investigations of atmospheric extinction using direct solar radiation measurements made with a multiple wavelength radiometer; J. Appl. Meteorol. 12 374-380.

Singh R P, Dey S, Tripathi S N and Tare V 2004 Variability of aerosol parameters over Kanpur, northern India; J. Geophys. Res. 109 D23206, doi: 10.1029/ 2004JD004966. 